\title{
Using real-time polymerase chain reaction as an alternative rapid method for enumeration of colony count in live Brucella vaccines
}

Waleed S. Shell ${ }^{1}$, Mahmoud L. Sayed ${ }^{1}$, A. A. Samy², Ghada Mohamed Al-Sadek ${ }^{1}$, Gina Mohamed Mohamed Abd El-Hamid ${ }^{1}$ and Abdel Hakam M. Ali ${ }^{1}$

\section{Central Laboratory for Evaluation of Veterinary Biologics, Cairo, Abbasia, Egypt; 2. Department of Microbiology and Immunology, National Research Center, Egypt. \\ Corresponding author: Waleed S. Shell, e-mail: tarikwaleedshell@hotmail.com, \\ Co-authors: MLS: m_lotfi8@hotmail.com, AAS: ayman_samy@hotmail.com,GMA: ghada.elsadek@yahoo.com, GMMAE: gina_mohammed@msn.com, AMA: hakam2060@gmail.com \\ Received: 28-01-2017, Accepted: 18-04-2017, Published online: 08-06-2017}

doi: 10.14202/vetworld.2017.610-615 How to citethis article: Shell WS, Sayed ML, Samy AA, Al-Sadek GM, El-Hamid GMMA, Ali AHM (2017) Using real-time polymerase chain reaction as an alternative rapid method for enumeration of colony count in live Brucella vaccines, Veterinary World, 10(6): 610-615.

\begin{abstract}
Aim: Brucellosis is a major bacterial zoonosis of global importance affecting a range of animal species and man worldwide. It has economic, public health, and bio-risk importance. Control and prevention of animal brucellosis mainly depend on accurate diagnostic tools and implementation of effective and safe animal vaccination program. There are three types of animal Brucella live vaccines - Brucella melitensis Rev-1 vaccine, Brucella abortus S19, and B. abortus RB51. Evaluation of these vaccines depends mainly on enumeration of Brucella viable count. At present, used colony count method is time consuming, costly and requires especial skills. Hence, the aim of this study is to use and standardize real-time polymerase chain reaction (RT-PCR) as an alternative, quantitative, sensitive, and rapid method to detect the colony count of Brucella in live Brucella vaccine.

Materials and Methods: Four batches of different live Brucella vaccines were evaluated using of conventional bacterial count and RT-quantitative PCR (RT-qPCR) using BSCP31 gene specific primers and probe. Standard curve was generated from DNA template extracted from 10-fold serial dilution of living B. abortus RB51 vaccine to evaluate the sensitivity of RT-qPCR.

Results: Results revealed that three batches of living Brucella vaccines were acceptable for Brucella colony count when traditional bacterial enumeration method was used. Results of RT-qPCR were identical to that of conventional bacterial count.
\end{abstract}

Conclusions: Results concluded that RT-qPCR was relatively sensitive compared to traditional bacterial colony count of these vaccines.

Keywords: Brucella, colony count, RB51, Rev-1, real-time polymerase chain reaction, S19, vaccines.

\section{Introduction}

Brucellosis is a major bacterial zoonosis of global importance affecting a range of different mammals including cattle, sheep, goats, swine, rodents, marine mammals, and man worldwide. In food animals, the disease primarily affects the reproductive system with concomitant loss in fertility and productivity of affected animals. In man, infection is characterized by recurrent febrile episodes that lead to the description of this disease as undulant fever (economic and public health importance) [1]. The severity of this disease and lack of vaccines suitable for use in man has led to the investigation of Brucella as agents for bioterrorism (bio-risk importance) [2]. Vaccines to be used for human are not yet available, and so eradication of

Copyright: Shell, et al. Open Access. This article is distributed under the terms of the Creative Commons Attribution 4.0 International License (http://creativecommons.org/licenses/by/4.0/), which permits unrestricted use, distribution, and reproduction in any medium, provided you give appropriate credit to the original author(s) and the source, provide a link to the Creative Commons license, and indicate if changes were made. The Creative Commons Public Domain Dedication waiver (http://creativecommons.org/ publicdomain/zero/1.0/) applies to the data made available in this article, unless otherwise stated. human brucellosis largely depend on the eradication of the disease in animals. Eradication of brucellosis in animals has been a goal for many countries. To control brucellosis, comprehensive vaccination, surveillance, and quarantine programs should be implemented. Both control and prevention procedures are highly dependent on accurate diagnostic tools and implementation of effective and safe animal vaccination programs [3].

There are three types of animal Brucella live vaccines - Brucella melitensis Rev-1 vaccine (0.5$2 \times 10^{9}$ colony forming unit $[\mathrm{CFU}] /$ dose) for vaccination of sheep and goats, Brucella abortus S19 (0.5-5 $\times 10^{9} \mathrm{CFU} /$ dose) for vaccination of cattle and buffaloes, and B. abortus RB51 (1-3.4 $\times 10^{10} \mathrm{CFU} /$ dose $)$ for vaccination of cattle and buffaloes. Evaluation of these vaccines depends mainly on enumeration of viable count, smoothness or roughness, safety test and potency test [4]. European Pharmacopoeia [5] reviewed that the dose of Rev-1 vaccine in sheep and goats should contain not fewer than $0.5 \times 10^{9}$ and not more than $4 \times 10^{9}$ live bacteria per dose.

At present, practiced colony count method is time consuming, costly and requires especial skills. 
Hence, the aim of this study was to use and standardize real-time polymerase chain reaction (RT-PCR) as a quantitative, sensitive, and rapid method to detect the colony count of live Brucella vaccine.

\section{Materials and Methods \\ Vaccines}

Eight lyophilized living Brucella vaccines of different batches (two B. abortus $\mathrm{S} 19$, four B. abortus RB51, and two B. melitensis Rev-1). The lyophilized vaccines were reconstituted in vaccine diluents and were used for bacteriological colony count and genomic DNA extraction.

\section{Bacterial colony count of living Brucella vaccines}

About $0.1 \mathrm{ml}$ of expected countable dilutions of different live Brucella vaccines were inoculated in five plates of tryptone soya agar and spread with a sterile glass. CFU per vaccine dose were enumerated according to protocols described previously $[4,6]$.

\section{Extraction of genomic DNA from Brucella strains}

Genomic DNA extraction from single dose of live Brucella vaccines for evaluation of Brucella viable count and from 10-fold serial dilutions of RB51 vaccine from $10 \times 10^{10}$ to $10 \times 10^{8} \mathrm{CFU} / \mathrm{ml}$ for generation of standard curve (RB51 vaccine vial of 5 doses $2 \times 10^{10} /$ dose were reconstituted on $1 \mathrm{ml}$ as $10 \times 10^{10} \mathrm{CFU} / \mathrm{ml}$ and the other one reconstituted on $1 \mathrm{ml}$ for serial dilution). Genomic DNA extraction was performed using G-spin Total DNA Extraction Kit (iNtRON) following the kit manufacturer's protocol.

\section{Oligonucleotide primers and probes used in RT-PCR}

Real-time PCR on tested samples was done using the primers and probe $[7,8]$ identifying and targeting the bcsp31 gene (GenBank accession number M20404) [7] (Table-1 and Figure-1).

\section{RT-PCR}

RT-PCR assay was standardized and performed in Stratagene MX3005P quantitative PCR (qPCR) system. The PCR Master Mix and PCR cycling conditions used are given in Tables-2 and 3.

\section{RT-PCR standard curves}

Standard curves were generated by plotting the cycle threshold values (CT) of the RT-qPCR performed on 10-fold serial dilutions of purified DNA from 10-fold serial dilutions of $B$. abortus RB51 vaccine $\left(10 \times 10^{10}-10 \times 10^{8} \mathrm{CFU} / \mathrm{ml}\right)$ against the log input cells/ml [9]. Brucella species concentrations were determined by the viable cell plate count method as mentioned above $[4,6]$.

\section{Results and Discussion}

In the absence of effective and safe human vaccine against brucellosis, animal vaccination against brucellosis is an important issue in control and eradication of brucellosis in animals and human. For more than 60 years, B. abortus S19 vaccine for buffaloes and cattle and $B$. melitensis Rev-1 vaccine for goats and sheep remain as the most efficient Brucella vaccines, and their use is of a great impact on the control and incidence of brucellosis in domestic ruminants and humans [10]. S19 and Rev-1 vaccines are used in vaccination of calves and ewes, respectively, in a dose of $0.5-2 \times 10^{9} \mathrm{CFU} /$ dose and $0.5-5 \times 10^{9} \mathrm{CFU} /$ dose [4]. Rev-1 vaccine can be used in a dose of $0.5-5 \times 10^{9} \mathrm{CFU} /$ dose [5]. RB51 vaccine strain was developed in 1982 by Prof. Gerhardt Schurig's group and is derived from a virulent smooth B. abortus biovar 1 strain 2308. RB51 vaccine is used in vaccination of cows in a dose of $1-3.4 \times 10^{10} \mathrm{CFU} /$ dose $[4,11]$. Evaluation of these vaccines depends mainly on identification of vaccinal strains, enumeration of Brucella viable count, safety and potency. Enumeration of Brucella viable count is time consuming and needs special skills [4]. This study was designed to use a RT-qPCR as alternative, sensitive, and rapid method to detect colony count in Brucella vaccines. Eight batches of Brucella vaccines, two B. abortus S19, four $B$. abortus RB51, and two B. melitensis Rev-1 were evaluated by conventional bacterial colony count and RT-qPCR.

By using conventional colony count, seven batches of living Brucella vaccines used in this study

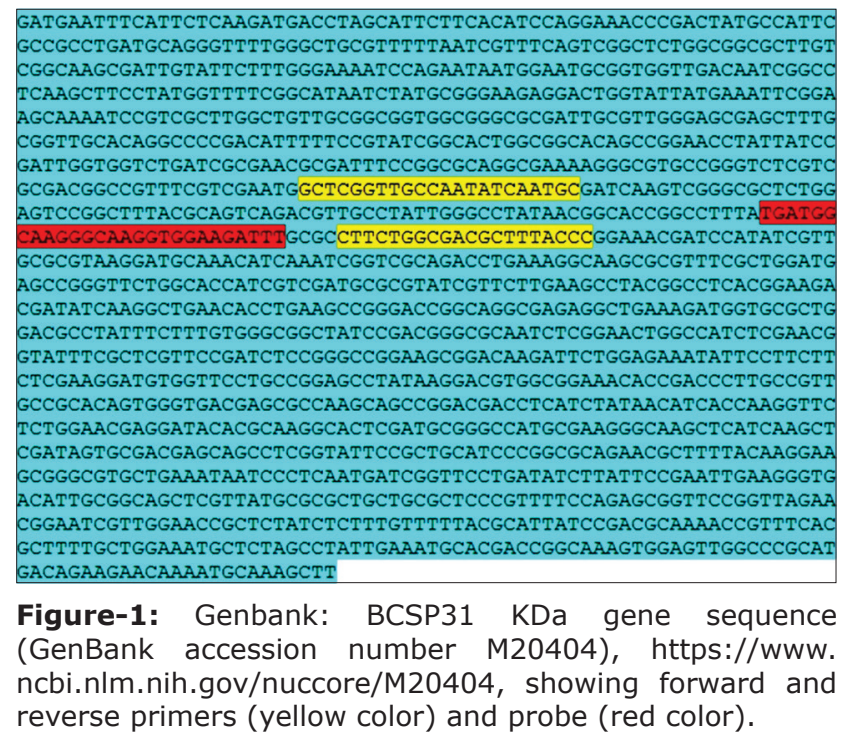

Table-1: RT-PCR oligonucleotides primers and probe of BCSF31 for Brucella species.

\begin{tabular}{llc}
\hline Primer & Sequence (5'-3') & Amplicon size (bp) \\
\hline BSCP31 Forward primer & GCTCGGTTGCCAATATCAATGC & 151 bp \\
BSCP31 Reverse primer & GGGTAAAGCGTCGCCAGAAG & \\
RT-PCR probe & AAATCTTCCACCTTGCCCTTGCCATCA-FAM/BHQ1 & \\
\hline
\end{tabular}

RT-PCR $=$ Real-time polymerase chain reaction

Veterinary World, EISSN: 2231-0916 
were with satisfactory results and within the standard international range of acceptable dose for animal's vaccination. On the other hand, one of the RB51 vaccine batches was unacceptable with colony count of $6 \times 10^{9} \mathrm{CFU} /$ dose as shown in Table- 4 .

In this study, bcsp31 gene was selected to be used in RT-qPCR for evaluation of colony count of living Brucella vaccines which is highly conserved gene among Brucella species and also used frequently as a gene target for diagnosis of human brucellosis [12-14], and therefore could potentially detect $B$. melitensis and $B$. abortus strains which were included in this study $[15,16]$. Moreover, it is specific method as it did not amplify DNA from any non-Brucella templates. The bcsp31 PCR was found to be $100 \%$ specific and was the most sensitive assay when compared with to omp2 and the 16S rRNA PCR [17]. BSCP31 PCR was used by many researchers for specific identification of genus Brucella from seropositive, active, relapsing, chronic cases in humans [18-20]. Furthermore, this gene target has been used specifically to detect Brucella in human cerebrospinal fluid, blood, and serum [21-23], in clinical tissues from seals [24] and in buffalo milk [25]. Many reports have been published

Table-2: Preparation of PCR master mix.

\begin{tabular}{lc}
\hline Component & Volume/reaction \\
\hline 2x QuantiTect Probe RT-PCR master & $12.5 \mu \mathrm{l}$ \\
mix & \\
Forward primer & $0.2 \mu \mathrm{l}(200 \mathrm{~mm})$ \\
Reverse primer & $0.2 \mu \mathrm{l}(200 \mathrm{~mm})$ \\
Probe & $0.1 \mu \mathrm{l}(100 \mu \mathrm{m})$ \\
DNase free water & $6.8 \mu \mathrm{l}$ \\
Template DNA & $5 \mu \mathrm{l}$ \\
\hline
\end{tabular}

$\mathrm{RT}-\mathrm{PCR}=$ Real-time polymerase chain reaction

Table-3: RT-PCR cycling conditions.

\begin{tabular}{lccc}
\hline Stage & Temperature & Time & Cycles \\
\hline $\begin{array}{l}\text { Primary } \\
\text { denaturation }\end{array}$ & $95^{\circ} \mathrm{C}$ & $10 \mathrm{~min}$ & 1 \\
$\begin{array}{l}\text { Amplification } \\
\text { Secondary } \\
\text { denaturation }\end{array}$ & $95^{\circ} \mathrm{C}$ & $30 \mathrm{~s}$ & 40 \\
$\begin{array}{l}\text { Annealing and } \\
\text { extension }\end{array}$ & $60^{\circ} \mathrm{C}$ & $90 \mathrm{~s}$ (optics on) & \\
\hline
\end{tabular}

$\mathrm{RT}-\mathrm{PCR}=$ Real time-polymerase chain reaction on the diagnostic efficiency of qPCR assays using bcsp31 gene for diagnosis of brucellosis in human samples [26] and also used for screening of brucellosis from camel serum [27].

TaqMan technology determines the PCR cycle at which the increase in fluorescence of the reporter dye reaches a CT is proportional to the log of the amount of target DNA and hence the log of the number of bacteria in the sample. Standard graph was based on B. abortus RB51 DNA extracted from tenfold serial dilution of RB51 vaccine (Figure-2). The RT-PCR assay with primers and probe specific for the Brucella BCSP31 gene was positive for all vaccine samples. The CT values were clearly inversely related to the quantity of organisms, especially during standard curve generation. These $\mathrm{CT}$ values corresponded to $10^{11} \mathrm{CFU}$ (positive at $\mathrm{CT}=16$ ) to $10^{9} \mathrm{CFU}$ (positive at $\mathrm{CT}=32$ ) of Brucella organism when the values were fit into the standard curve generated by using the results for serial dilutions of RB51 vaccine. Colonies count $10^{11}-10^{9}$ CFU represents the range of acceptable colonies count of all type of Brucella vaccines $\left(1 \times 10^{9} \mathrm{CFU} /\right.$ dose in case of Rev-1 vaccine to $3.4 \times 10^{10} \mathrm{CFU} /$ dose in case of RB51 vaccine) (Figure-3).

As shown in Figures-2 and 3 and Table- 4 , results of RT-qPCR were in agreement with results of traditional bacterial colony count except with one batch of Rev-1 vaccine where results of traditional colony count and RT-qPCR were $3 \times 10^{9} / \mathrm{CFU} /$ dose and $5.163 \times 10^{\%} /$ CFU/dose, respectively, but still results within the same $\log$. Results of qPCR were with sensitivity of $87.5 \%$. Findings confirmed that the unaccepted batch of RB51 vaccine by traditional colony count was out of standard international range of $B$. abortus RB51 vaccine.

Results agree with Angel et al. [28] who used RT-qPCR for enumeration of acetic acid bacteria with $100 \%$ sensitivity when compared with plating and microscope counting also was in agreement with Chaloemnon et al. [29] who enumerated the gastrointestinal microbiota (Lactobacilli, Bifidobacteria, and Escherichia coli) in weaning pigs by conventional culture and RT-PCR. Aline et al. [30] and Susan et al. [9]. Found high agreement with the results of traditional colony count and RT-qPCR when used to

Table-4: Brucella count by traditional methods and RT-qPCR based on a standard graph generated by brucella RB51 DNA within the range.

\begin{tabular}{|c|c|c|c|c|}
\hline $\begin{array}{l}\text { Brucella vaccines } \\
\text { samples }\end{array}$ & CT & $\begin{array}{c}\text { Estimation of brucella vaccines } \\
\text { by rt-PCR }\end{array}$ & $\begin{array}{l}\text { Brucella viable count by traditional } \\
\text { methods }\end{array}$ & Acceptance \\
\hline RB51 & 21.69 & $2.89 \times 10^{10} \mathrm{CFU} /$ dose & $3.4 \times 10^{10} \mathrm{CFU} /$ dose & Accepted \\
\hline RB51 & 23.00 & $1.25 \times 10^{10} \mathrm{CFU} /$ dose & $3.4 \times 10^{10} \mathrm{CFU} /$ dose & Accepted \\
\hline RB51 & 22.14 & $2.325 \times 10^{10} \mathrm{CFU} /$ dose & $1.2 \times 10^{10} \mathrm{CFU} /$ dose & Accepted \\
\hline RB51 & 28.65 & $4.19 \times 10^{9} \mathrm{CFU} / \mathrm{dose}$ & $6 \times 10^{9} \mathrm{CFU} / \mathrm{dose}$ & Not accepted \\
\hline S19 & 27.98 & $5.025 \times 10^{9} \mathrm{CFU} /$ dose & $4 \times 10^{9} \mathrm{CFU} /$ dose & Accepted \\
\hline S19 & 31.52 & $1.6 \times 10^{9} \mathrm{CFU} /$ dose & $4.8 \times 10^{9} \mathrm{CFU} / \mathrm{dose}$ & Accepted \\
\hline Rev-1 & 27.87 & $5.163 \times 10^{9} \mathrm{CFU} /$ dose & $3 \times 10^{9} \mathrm{CFU} /$ dose & Accepted \\
\hline Rev-1 & 32.00 & $1 \times 10^{9} \mathrm{CFU} /$ dose & $1.5 \times 10^{9} \mathrm{CFU} /$ dose & Accepted \\
\hline
\end{tabular}

RT-qPCR=Real-time quantitative polymerase chain reaction, $C F U=$ Colony forming unit, $C T=C y c l e$ threshold 


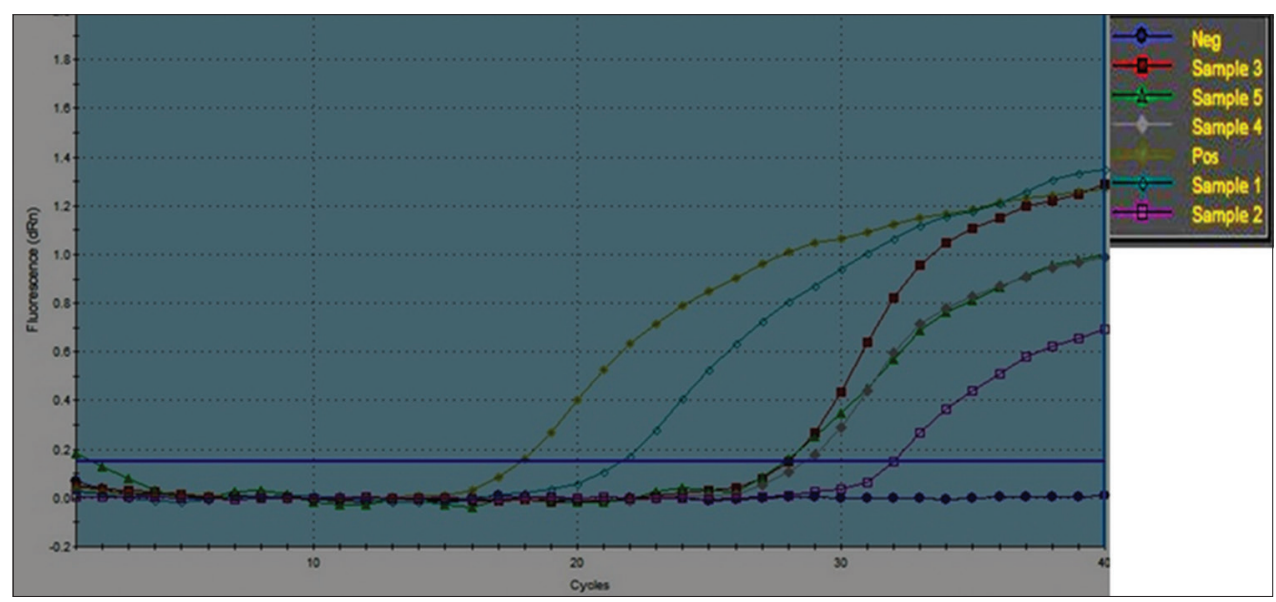

Figure-2: Amplification curves of real time-quantitative polymerase chain reaction for quantification of Brucella vaccine batches. Sample $1=$ RB51 vaccine, sample $2=$ Rev- 1 vaccine, sample $3=$ RB5 1 vaccine, sample $4=$ S 19 vaccine and sample $5=\mathrm{S} 19$ vaccine.

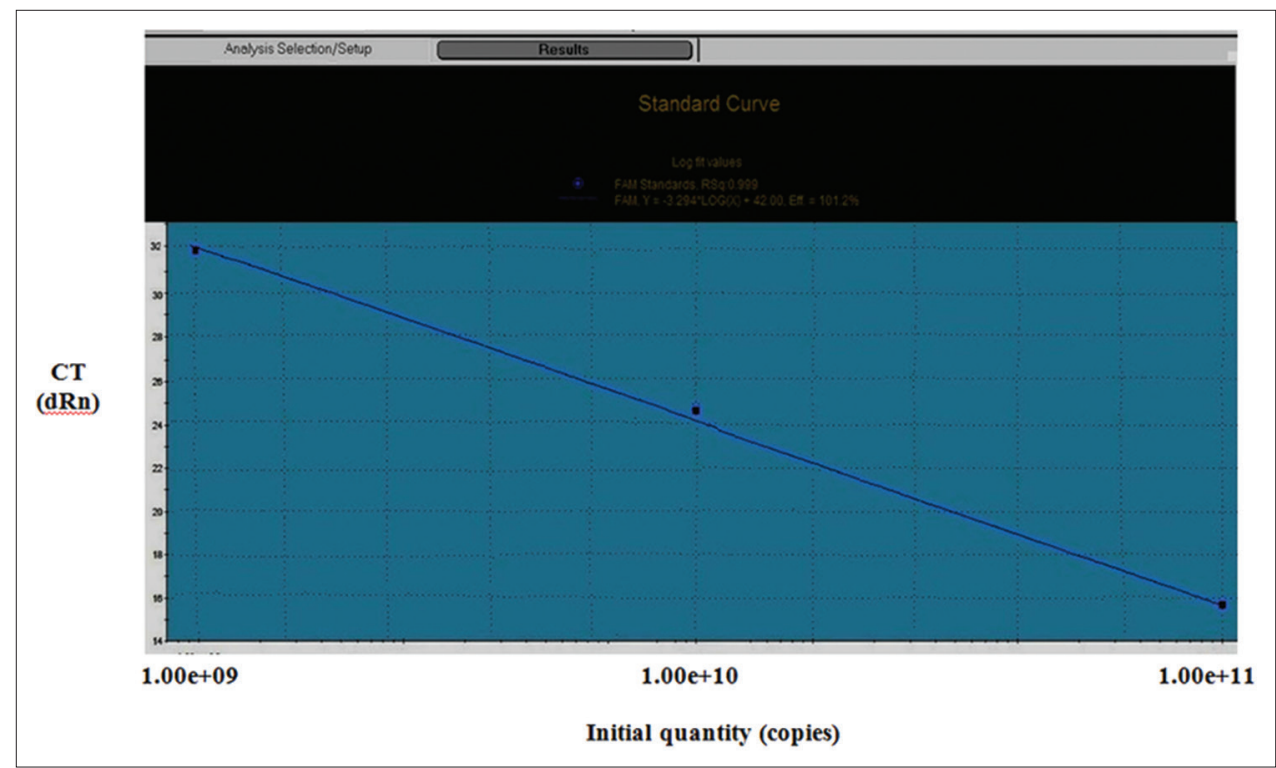

Figure-3: Schematic standard curve of a dilution series, plotting cycle threshold values over log template concentrations. The slope is used to estimate number of Brucella colonies/vaccine samples.

enumerate Lactobacillus helveticus in dairy products and Streptococcus pneumoniae, respectively.

In disagreement with these results, Botaro et al. [31] reviewed that the qPCR protocol can be used as a rapid diagnostic assay to accurately detect Staphylococcus aureus from bovine milk, but this protocol is not accurate for counting of $S$. aureus in bronopol-preserved milk samples from naturally infected mammary glands. Same findings were revealed from enumeration of living E. coli $\mathrm{O} 157: \mathrm{H} 7$ on plants [32].

A major drawback of qPCR is its inability to differentiate the DNA from viable and dead cells, and this is a critical factor for many researches' especially in the food industry, water pollution researches, so to remedy this shortcoming, researchers have used biological dyes such as ethidium monoazide and propidium monoazide to pre-treat samples before DNA extraction which is important issue especially in food industry $[32,33]$.

Results of this study may be more applicable than other studies which used RT-PCR for identification of organisms from tissues, water, etc., which may give false results due to nonspecific reactions which especially occurs when RT-PCR used for identification of multiple organisms using universal primers sets. However, in this study, we evaluated vaccines which contain one organism type (Brucella) as these vaccines were tested for sterility before counting process. Furthermore, although RT-PCR measure the total number of living and dead (dead cells as a results of freeze drying process) Brucella cells, but due to all these vaccines are subjected to the same factors as freeze drying program so ratio of living to dead cells were nearly constant and so it would not have an effect on the sensitivity of the RT-PCR.

\section{Conclusions}

In this study, RT-qPCR assay was developed to enumerate colony count in live Brucella vaccines using DNA template extracted from tenfold serial dilutions of different living Brucella vaccines. The 
assay proved to be highly specific and sensitive when compared with traditional bacterial colony count of these vaccines. However, it needs more standardization, validation, and evaluation by using more batches of different live bacterial vaccines such as Brucella vaccines, E. coli (Poulvacpoultry vaccine), Salmonella vaccine (Megan VAC-1, poultry vaccine), and Streptococcus equi vaccine (PINNACLE ${ }^{\circledR}$ I.N, horse vaccine) and evaluate the sensitivity of standard curves generated from DNA template extracted from tenfold serial dilutions of different living bacterial vaccines and from 10-fold serial dilution of template DNA.

\section{Authors' Contributions}

All authors designed and planned this research work. DNA extraction from different live Brucella vaccine batches and from serial dilution of control positive live Brucella vaccine batch were carried out by AAS, GMA, GMMAE and AMA. Traditional Colony count of different live Brucella vaccines batches was performed by all authors. RT-PCR on different live Brucella vaccines batches and construction of standard curve to estimate bacterial count in vaccine batches were carried out by WSS, MLS, AAS and AMA. All authors contributed equally in preparation and revision of the manuscript and collection of scientific papers related to the subject of this research. All authors read and approved the final manuscript.

\section{Acknowledgments}

Central Laboratory for Evaluation of Veterinary Biologics, Egypt funded all materials used in this study. Appreciation is expressed to all the technical staff of Microbiology Department of Central Laboratory for Evaluation of Veterinary Biologics for their contribution in the practical part of this study.

\section{Competing Interests} interests.

The authors declare that they have no competing

\section{References}

1. Vipan, K., Parveen, K., Heigo, P., Hanish, S. and Wadhawan, V.M. (2015) Brucellosis: A neglected enemy. Int. J. Curr. Med. Pharm. Res., 1(7): 91-93.

2. Noormohamad, M. and Mohammad, R.P. (2016) Vaccines and vaccine candidates against brucellosis. Infect. Epidemiol. Med., 2(4): 32-36.

3. Corbel, M.J. (2006) Brucellosis in humans and animals. World Health Organization Collaboration with the Food and Agriculture Organization of the United Nations and World Organization for Animal Health. World Health Organization, Geneva, Switzerland.

4. OIE. (2016) Brucellosis (Brucella abortus, Brucella melitensis and Brucella suis). Manual of Diagnostic Tests and Vaccines for Terrestrial Animals. Ch. 2.1.4. OIE, Paris.

5. European Pharmacopoeia. (2005) General Notices (1) Apply to All Monographs and other Texts, Brucellosis Vaccine (Live) (Brucella melitensis Rev. 1 Strain), Freeze-Dried, for Veterinary Use. European Pharmacopoeia, 04/2005:0793.

6. Alton, G.G., Jones, L.M., Angus, R.D. and Verger, J.M. (1988) Techniques for the Brucellosis Laboratory. Vol. 24.
Institute National de la Recherche Agronomique, Paris.

7. Elena, A., Mohammad, F., Tamer, E., Israr, S., Kamel, A., Issa, R., Assad, M., Stelian, B., Maria, R.G. and Doina, D. (2016) Validation of RT-qPCR technique for detection of Brucella genome in milk sheep and goat in west bank part of palestine. Sci. Bull. Ser. F Biotechnol., XX: 321-328.

8. Probert, W., Schrader, K., Khuong, N., Bystrom, S. and Graves, M. (2004) Real-time multiplex PCR assay for detection of Brucella spp., B. abortus, B. melitensis. J. Clin. Microbiol., 42: 1290-1293.

9. Susan, C.M., Jim, F.H., David, R.M. and Anthony, G.S.J. (2014) Making standards for quantitative real-time pneumococcal PCR. Biomol. Detect. Quantif., 2: 1-3.

10. Blasco, J.M. (1997) A review of the use of B. melitensis Rev 1 vaccine in adult sheep and goats. Prev. Vet. Med., 31: 275-283.

11. Elaine, M.S.D., Nammalwar, S. and Andrey, P.L. (2015) Recent advances in Brucella abortus vaccines. Vet. Res., 46: 76 .

12. Al Dahouk, S., Fleche, P.L., Nockler, K., Jacques, I., Grayon, M., Scholz, H.C., Tomaso, H., Vergnaud, G. and Neubauer, H. (2007) Evaluation of Brucella MLVA typing for human brucellosis. J. Microbiol. Methods, 69: 137-145.

13. Navarro, E., Escribano, J., Fernandez, J.A. and Solera, J. (2002) Comparison of three different PCR methods for detection of Brucella spp. In human blood samples. FEMS Immunol. Med. Microbiol., 34: 147-151.

14. Morata, P., Queipo-Ortuno, M.I., Reguera, J.M., Garcia-Ordonez, M.A., Cardenas, A. and Colmenero, J.D. (2003) Development and evaluation of a PCR-enzyme linked immunosorbent assay for diagnosis of human brucellosis. J. Clin. Microbiol., 41: 144-148.

15. Bricker, B.J., Tabatabai, L.B., Deyoe, B.L. and Mayfield, J.E. (1988) Conservation of antigenicity in a $31 \mathrm{kDa}$ Brucella protein. Vet. Microbiol., 18: 313-325.

16. OIE (World organization of Animal Health). (2014) Manual of Diagnostic Tests and Vaccines for Terrestrial Animals (Mammals, Birds and Bees). OIE, Paris.

17. Mukherjee, F., Jain, J., Patel, V. and Nair, M. (2007) Multiple genus specific markers in PCR assays improve the specificity and sensitivity of diagnosis of brucellosis in field animals. J. Med. Microbiol., 56: 1309-1316.

18. Kattar, M.M., Zalloua, P.A., Araj, G.F., Samatha-Kfoury, J., Shbaklo, H., Kanj, S.S., Khalife, S. and Deeb, M. (2007) Development and evaluation of real time polymerase chain reaction assays on whole blood and paraffin-embedded tissues for rapid diagnosis of human brucellosis. Diagn. Microbiol. Infect. Dis., 59: 23-32.

19. Mitka, S., Anetaki, S.C., Souliou, E. Diza, E. and Kansouzidou, A. (2007) Evaluation of different PCR assay for the early detection of acute and relapsing human brucellosis in comparison with conventional methods. J. Clin. Microbiol., 45: 1211-1218.

20. Queipo-Ortuno, M.I., Colmenero, J.D., Bravo, M.J., Garcia-Ordonez, M.A. and Morata, P. (2008) Usefulness of a quantitative real-time PCR assay using serum samples to discriminate between inactive, serologically positive and active human brucellosis. Clin. Microbiol. Infect., 14: $1128-1134$

21. Debeaumont, C., Falconnet, P.A. and Maurin, M. (2005) Real-time PCR for detection of Brucella spp. DNA in human serum samples. Eur. J. Clin. Microbiol. Infect. Dis., 24: 842-845.

22. Colmenero, J.D., Clavijo, E., Morata, P., Bravo, M.J. and Queipo-Ortuno, M.I. (2011) Quantitative real-time polymerase chain reaction improves conventional microbiological diagnosis in an outbreak of brucellosis due to ingestion of unpasteurized goat cheese. Diagn. Microbiol. Infect. Dis., 71: 294-296.

23. Sohrabi, M., Mobarez, A.M., Behmanesh, M., Khoramabadi, N. and Doust, R.H. (2011) Evaluation of a new set of real-time PCR for Brucella detection within 
human and animal samples. J. Pharm. Health Sci., 1: 13-17.

24. Sidor, I.F., Dunn, J.L., Tsongalis, G.J., Carlson, J. and Frasca, S.Jr. (2013) A multiplex real-time polymerase chain reaction assay with two internal controls for the detection of Brucella species in tissues, blood and feaces from marine mammals. J. Vet. Diagn. Invest., 25: 72.

25. Amoroso, M.G., Salzano, C., Cioffi, B., Napoletano, M., Garofalo, F., Guarino, A. and Fusco, G. (2011) Validation of a real time PCR assay for fast and sensitive quantification of Brucella spp. In water buffalo milk. Food Control, 22: 1466-1470.

26. Sanjuan-Jimenez, R., Morata, P., Bermudez, P., Bravo, M.J. and Colmenero, J.D. (2013) Comparitive clinical study of different multiplex real-time PCR strategies for the simultaneous differential diagnosis between extrapulmonary tuberculosis and focal complications of Brucellosis. PLoS Negl. Trop. Dis., 7: e2593.

27. EI Behiry, A. (2014) Evaluation of diagnostic techniques and antimicrobial resistance of Brucella spp. Isolated from blood serum of camels and camel ranchers. J. Microbiol. Res., 4: 104-111.

28. Angel, G., Nuria, H., Montserrat, P., Albert, M. and
Jose M.G. (2006) Enumerationand detection of acetic acid bacteria by real-time PCR and nested PCR. FEMS Microbiol. Lett., 254: 123-128.

29. Chaloemnon, P., Chomnawang, M.T., Junlapho, W. and Paraksa, N. (2016) Application of real-time PCR for quantifying gastrointestinal microbiota in weaning pigs influenced by dietary feed additive supplementation. Thai J. Vet. Med., 46(1): 23-32.

30. Aline, M., Helene, B., Elisabeth, E., Leo, M. and Irmler, S. (2017) Detection and enumeration of Lactobacillus helveticus in dairy products. Int. Dairy J., 68: 52-59.

31. Botaro, B.G., Cortinhas, C.S., Março, L.V., Moreno, J.F.G., Silva, L.F.P., Benites, N.R. and Santos, M.V. (2013) Detection and enumeration of Staphylococcus aureus from bovine milk samples by real-time polymerase chain reaction. J. Dairy Sci., 96(11), 6955-6964.

32. Zeng, D., Chen, Z., Jiang, Y., Xue, F. and Li, B. (2016) Advances and challenges in viability detection of foodborne pathogens. Front. Microbiol., 7: 1-12.

33. Ju, W., Moyne, A. and Marco, M.L. (2016) RNA-based detection does not accurately enumerate living Escherichia coli O157:H7 cells on plants. Front. Microbiol., 7: 1-9.

$* * * * * * * *$ 